\title{
Single conversion audio amplifier and DC-AC converters with high performance and low complexity control scheme
}

\section{Poulsen, Søren; Andersen, Michael Andreas E.}

Published in:

2004 IEEE 35th Annual Power Electronics Specialists Conference

Link to article, DOI:

10.1109/PESC.2004.1355753

Publication date:

2004

Document Version

Publisher's PDF, also known as Version of record

Link back to DTU Orbit

Citation (APA):

Poulsen, S., \& Andersen, M. A. E. (2004). Single conversion audio amplifier and DC-AC converters with high performance and low complexity control scheme. In 2004 IEEE 35th Annual Power Electronics Specialists Conference (pp. 267-271). IEEE. https://doi.org/10.1109/PESC.2004.1355753

\section{General rights}

Copyright and moral rights for the publications made accessible in the public portal are retained by the authors and/or other copyright owners and it is a condition of accessing publications that users recognise and abide by the legal requirements associated with these rights.

- Users may download and print one copy of any publication from the public portal for the purpose of private study or research.

- You may not further distribute the material or use it for any profit-making activity or commercial gain

- You may freely distribute the URL identifying the publication in the public portal 


\section{Single conversion audio amplifier and DC-AC converters with high performance and low complexity control scheme}

\author{
Søren Poulsen \\ Ørsted-DTU, Automation \\ Technical University of Denmark \\ Lyngby, Denmark \\ spo@oersted.dtu.dk
}

\author{
Michael A. E. Andersen \\ Ørsted·DTU, Automation \\ Technical University of Denmark \\ Lyngby, Denmark \\ ma@oersted.dtu.dk
}

\begin{abstract}
This paper proposes a novel control topology for a mains isolated single conversion audio amplifier and DC-AC converters. The topology is made for use in audio applications, and differs from prior art in terms of significantly reduced distortion as well as lower system complexity. The topology can be useful in a wide range of DC-AC applications such as motor drives or UPS systems requiring mains isolation as well.
\end{abstract}

\section{INTRODUCTION}

Switch mode audio amplifiers are beginning to show up on market in still greater numbers. Several different types of switch mode amplifiers are required for the different segments of the market. Stand-alone applications such as active subwoofer applications can be benefited by use of single conversion amplifiers. Mains isolated single conversion amplifiers are generally more complex amplifier topologies than non-isolated amplifiers, but because no mains isolated power supply is required for such an application, the overall complexity and cost is reduced, as well as the total system efficiency is increased.

In prior art [1-12] a number of different single stage amplifiers / DC-AC converters have been proposed, but most of these suffer from a high complexity control scheme as well as high distortion, which is a critical parameter in audio applications. The topology proposed in this paper is a high performance single conversion amplifier with a very low complexity in the power layout as well as for the control system required.

\section{A. Basic operation}

Isolated single conversion amplifiers can be divided into two subcategories, one using a low frequency transformer to obtain the mains isolation [1], the other using a high frequency transformer [2-13]. The obvious benefits by using a high frequency transformer is reduced size and hereby, cost.

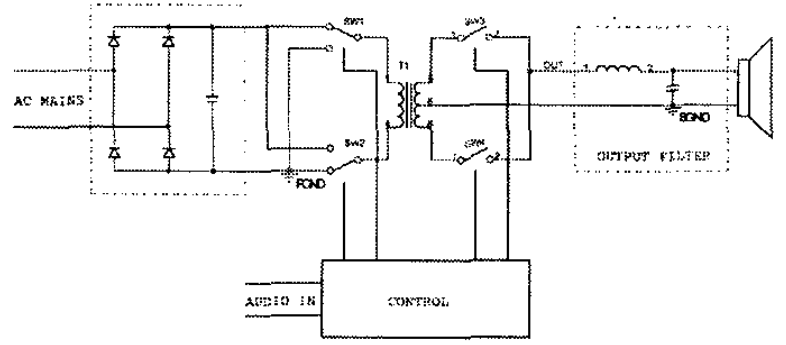

Figure 1 Basic single conversion amplifier using $\mathrm{HF}$ transformer

Figure 1 shows an illustration of the basic hardware architecture of a single conversion amplifier isolated by a high frequency transformer. The primary side switches, SW1 and SW2 can be realized with different topologies, e.g. push-pull or a full-bridge stage. The secondary side is shown with a tapped transformer winding and bi-directional single rectification, but can be made with a single transformer winding and a bi-directional full-bridge rectifier.

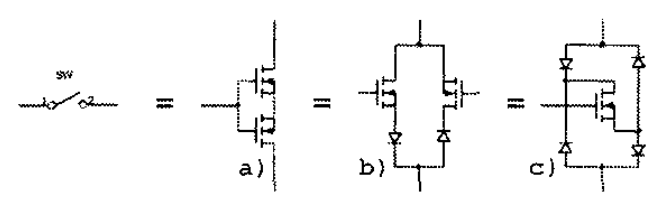

Figure 2 Secondary side bi-directional switch implementations

Figure 2 shows different implementations of a bi-directional switch. By using two MOSFETs in anti-series (a) one (b) or two (c) series diodes are avoided, reducing distortion due to the resulting linear, resistive, on-characteristic.

Different topologies using high frequency transformers have been proposed in the prior art. The basic operation of these can be divided into two sub-groups, one using a $50 \%$ duty cycle signal on the transformer primary and having a phase shifted secondary side generation of the audio-PWM signal $[2,3]$, the other using a 3-level modulated signal with every second pulse inverted [4-13], thus reducing the low frequency content of the PWM signal, on the transformer primary, and with a secondary side bi-directional rectification. 

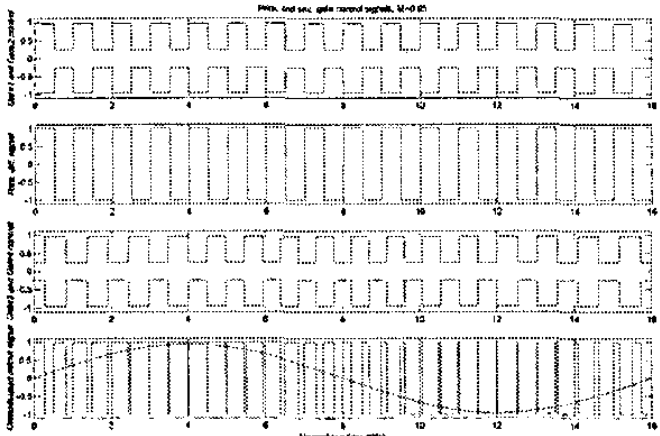

Figure 3 Control scheme for single conversion amplifier with constant $50 \%$ duty cycle on transformer primary, the gate signals refers to SW1-4 on Figure 1

Figure 3 shows a modulation scheme using a $50 \%$ signal on the transformer's primary side. The modulation index of the audio signal, $\mathrm{M}$, is 0.95 , and the switching frequency, $\mathrm{fs}$, is 16 times the audio frequency. The PWM signal is made by phase-shifting the $50 \%$ duty cycle secondary signals with respect to the primary side signals. The PWM signal in this control scheme is a 2-level modulated signal. In this approach the magnetization of the transformer is at the same maximum level at all audio signal levels, leading to a constant core loss in the transformer.
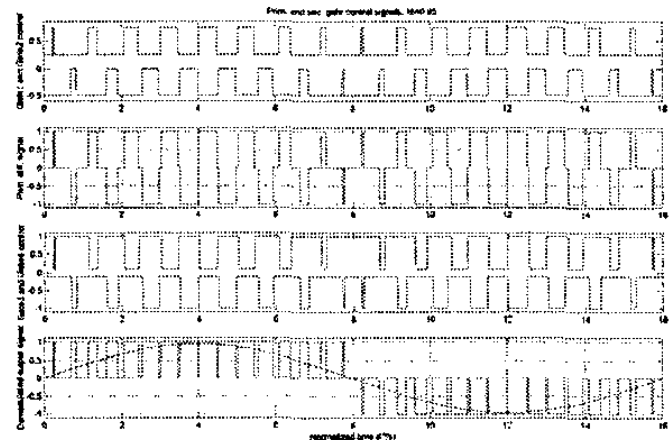

Figure 4 Control scheme for single conversion amplifier using 3-level modulation with every second pulse inverted on the transformer primary, the gate signals refers to SWI-4 on Figure 1

Figure 4 shows a control scheme from prior an [4]. It is seen that the correct polarity of the audio output is made by inverting the secondary side control signals for one polarity of the audio signal. The PWM signal in this scheme is a 3level modulated signal, and the magnetization of the transformer follows $\mathrm{M}$, the modulation index of the audio signal, leading to ideally no core loss at idle. The EMI problems with high frequency components on the output is significantly reduced even if using an L-C ouput filter when using 3-level modulation compared to 2-level modulation, because of the high frequency components are fewer and are directly dependent on the modulation index as illustrated on Figure 5-Figure 8 which shows FFT specters of the differential output for different values of $M$ with the switching frequency, fs 16 times higher than the audio frequency.

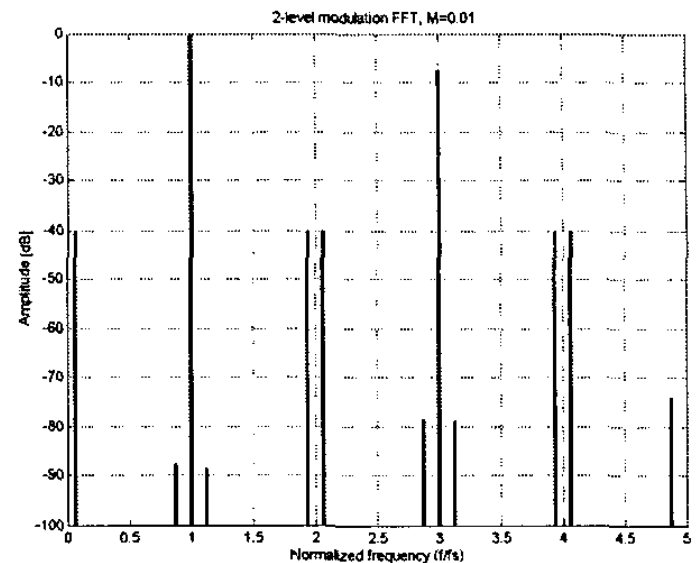

Figure 5 PWM FFT spectrum, 2-level, $M=0.01$

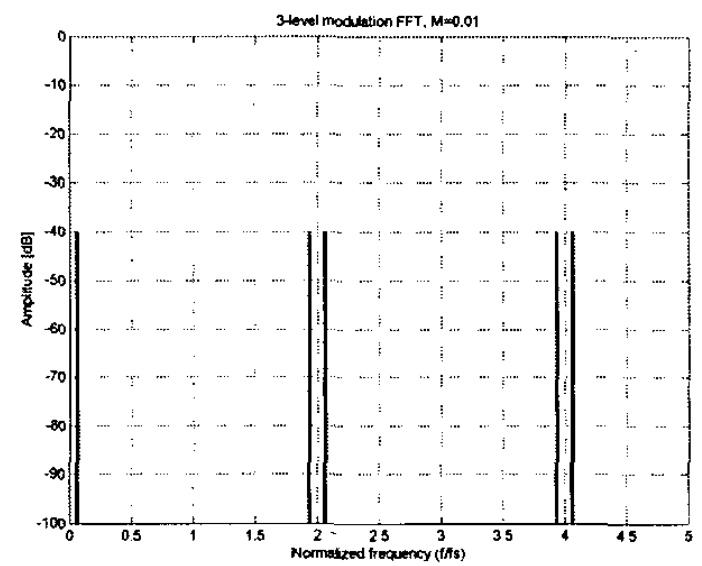

Figure 6 PWM FFT spectrum, 3-level, $M=0.01$ 


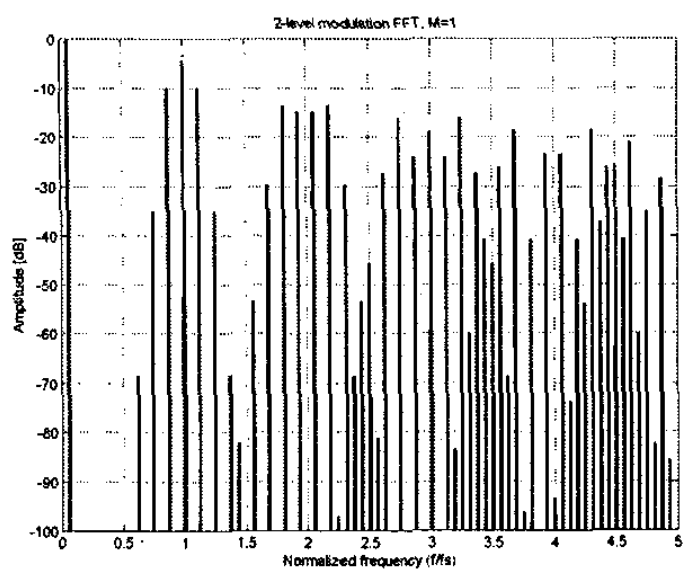

Figure 7 PWM FFT spectrum, 2-level, $M=1$

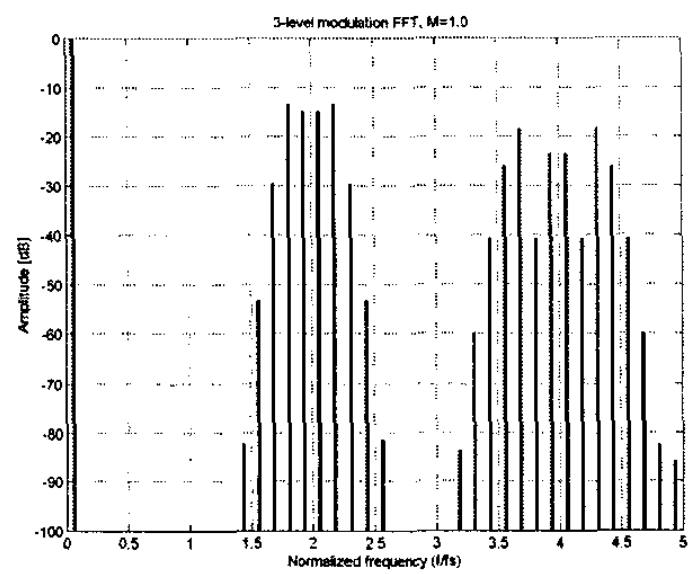

Figure 8 PWM FFT spectrum, 3-level, $M=1$

The control scheme proposed in this paper uses a 3-level modulated signal with every second pulse inverted, and a secondary side bi-directional rectification, which means that the differential signal on the transformer's primary side is identical to the approach shown in Figure 4. The proposed control scheme is shown in Figure 9.

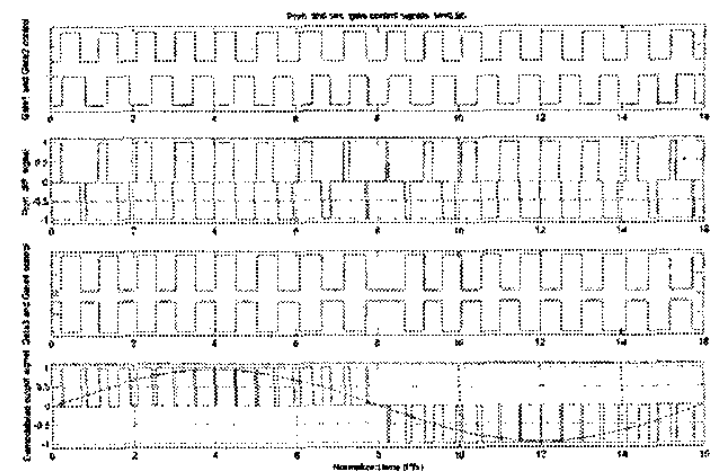

Figure 9 Control scheme for the proposed topology, the gate signals refers to SW $1-4$ on Figure 1

The way the control scheme differs from the one in Figure 4 is the generation of the primary side differential signal and the control signals for the secondary side rectifiers, by using only $50 \%$ duty cycle signals. This gives the significant benefits:

- The performance is not affected significantly by finite slopes of the pulses on the transformer primary

- All gate-drive signals have a $50 \%$ duty cycle, reducing gate drive complexity by allowing gate transformers without any low frequency saturation problems

- Soft-switching on the secondary side bi-directional rectifiers can easily be obtained

On Figure 4 each of the control signals for both primary and secondary side changes on both edges of every second pulse of the PWM signal, which leads to very narrow pulses for small input signal levels. Because of the finite slopes on the outputs of the primary side switching stages as well as the output of the transformer, a significant amount of distortion will occur especially at low modulation indexes that results in a short pulse width. In Figure 9 the two primary side gate signals are both $50 \%$ duty cycle signals, where one is phase shifted with respect to the other. If the positive and the negative slopes of the output signal of the primary power stages respectively can be considered identical, the area of each pulse (voltage time) will not be affected at all, ensuring very low distortion levels even at low modulation indexes. This will be the case if the positive and negative slopes from the primary switching legs respectively can be considered identical, giving high immunity to distortion caused by imperfect switching.

The secondary side gate signals are once again with $50 \%$ duty cycle, and the two signals are identical, but out of phase, ensuring correct rectification of the output pulses from the transformer secondary. For one polarity of the audio signal, the secondary side gate signals are inverted, ensuring right polarity of the output signal. The allowed use 
of simple gate transformer circuits on the secondary side significantly reduce system complexity, because the gate signals should be referred to the output signal, making use of solid state gate drive complicated. By applying a time-delay between the transitions of the secondary side and the primary side gate signals, so the secondary gate signals are changed before the primary side, the secondary side switches are changed at ZVS since the output voltage from the transformer is zero.

The secondary side soft switching is illustrated in Figure 10 where it can be seen that the primary side control signals are delayed with respect to the secondary side control signals, with the result that the secondary side switches is turned on and off at ZVS. By delaying the turn off of the secondary side rectifying switches, a continuous conducting path is ensured, thus avoiding ringing and thereby need for snubber networks.

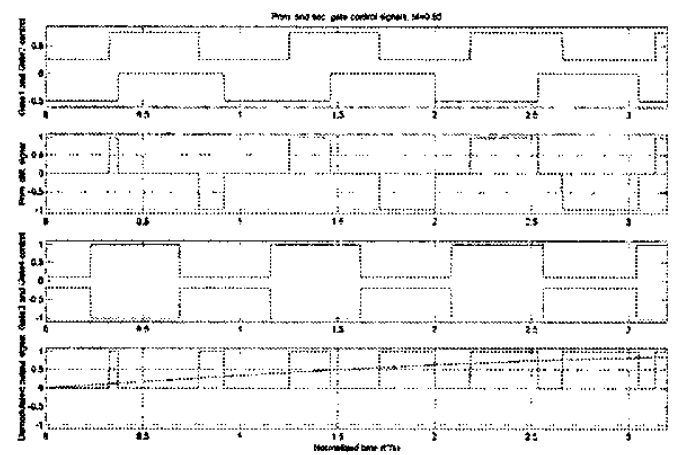

Figure 10 Secondary side bi-directional rectifier soft switching

\section{I. EXPERIMENTAL RESULTS}

A prototype of the proposed converter has been build to verify the operation. The amplifier was designed for driving a low impedance load.

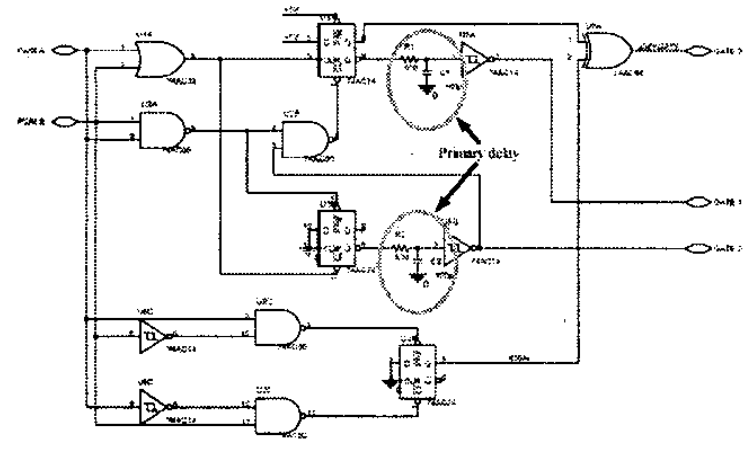

Figure 11 Control logic used in the prototype

As shown in Figure 11, the complexity of the control logic, generating the gate signals, can be realized relatively simple, still achieving correct operation as well as self resetting capabilities e.g. in case of periodic failure caused by noise.
Figure 12 shows a picture of the prototype amplifier. Because of the secondary side softswitching no heatsink is attached to the secondary side switches.

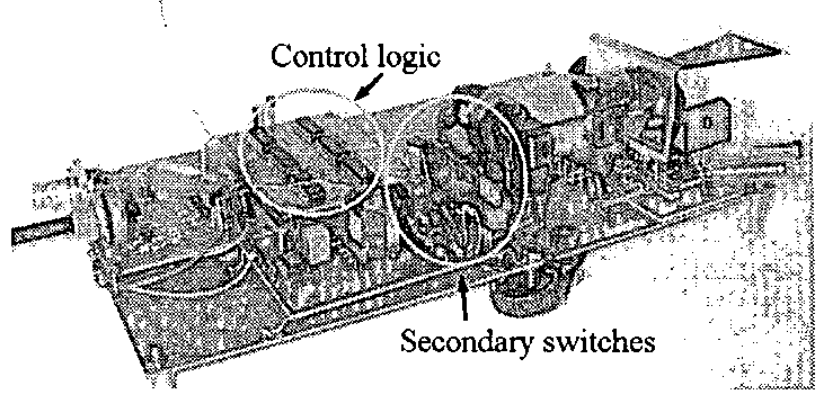

Figure 12 Single conversion amplifier prototype

Parameters for the prototype amplifier is:

- Umains=230VAC

- $\mathrm{fs}=200 \mathrm{kHz}$

- Output power: $100 \mathrm{~W}$ into $1 \Omega(15 \mathrm{~V}$ maximum output voltage)

- Power bandwidth (output filter cut-off) $=60 \mathrm{kHz}$

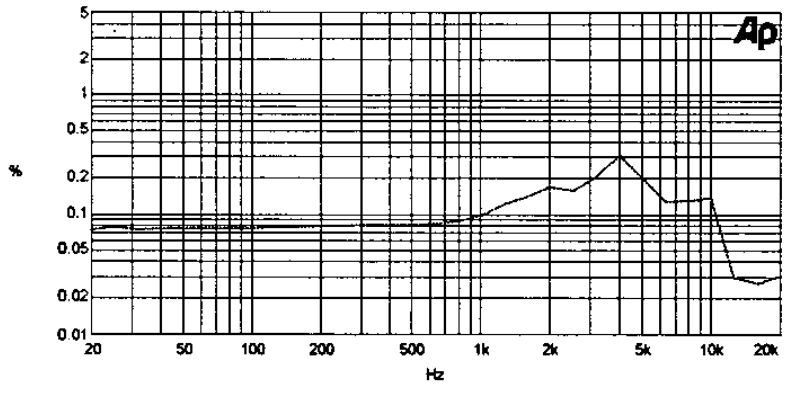

Figure 13 THD+noise vs. frequency for the prototype amplifier, $\mathrm{BW}=\mathbf{2 0 \mathrm { kHz }}$

Figure 13 shows audio performance for the prototype amplifier. The performance level obtained is suitable for applications with full audio bandwidth. The preliminary prototype is a non-optimized implementation built only to prove the operational principles. 


\section{CONCLUSION}

A single conversion mains isolated audio amplifier and $\dot{D} \dot{C}$ $\mathrm{AC}$ inverter control scheme has been proposed. The control scheme differs from prior art in both increased performance and reduced system complexity. Because the pulses on the transformer's primary is made by either two positive or negative going transitions in the primary power stage, the resulting pulse area (voltage time) is not affected by finite slopes, as long as the two slopes are considered identical. Further more all gate signals on both the primary and secondary side are $50 \%$ duty cycle signals allowing use of simple gate transformers without saturation problems. Total energy efficiency is high due to soft switching capabilities on the secondary side bi-directional rectifying switches.

\section{ACKNOWLEDGMENTS}

The work presented in this paper is some of the results from an on-going Ph.D. research project, ACT - ACtive Transducers, at Technical University of Denmark, financed by The Danish Energy Authority, journal number 1273/01006. The project is in co-operation with Bang \& Olufsen ICEpower A/S and Danish Sound Technology A/S.

\section{REFERENCES}

[1] Daniel Mitchell: "Modern Power Conversion Design Techniques. Segment One. Switching Regulator design \& Analysis Methods" pp. 83.

[2] Brian E. Attwood, Larry E. Hand, Lee C. Santillano: Audio Amplifier With Phase Modulated Modulation US 4,992,751 US patent, Oct. 1989

[3] Terris L. Pennington: Synchronous Modulation Circuit, US 4,882,664, US patent, Jun. 1988

[4] Daniel Mitcheil: DC to Low Frequency Inverter With Pulse Width Modulated High Frequency Link, US 4,339,791, US patent, Jul. 1982

[5] Fred Mirow: Switching Amplifier System, US 4,573,018, US patent, Apr. 1984

[6] P. Espinosa, L. Huber, F. C. Lee and W. A. Tabisz: "Study of Topologies for High-Current Bipolar Magnet Power Supplies" APEC'94, pp. 869-875.

[7] D. L. R. Vidor and A. J. Perin: "A Soft Commutation Constant High Frequency Link DC/AC Converter operating with Sinusoidal Output Voltage" PESC'94, pp. 637-643.

[8] Tranh T. Nguyen: Clas-N Amplifier, US $6,496,059 \mathrm{~B} 1$, US patent, Nov. 2000

[9] Paul Rebers te Enschede: Klasse-D versterker met galvanische scheiding, NL 1014065, Dutch patent, Jul. 2001

[10] Lars P. Allfather: Reduced swithing losses in a phase-modulated switch-mode amplifier, US 5,542,827, US patent, Jul. 1996

[11] David Gurwicz, Lawrence John Berman: Static inverter, GB 2087171 A, UK patent, May 1982
[12] Yamato Ikou, Tokunaga Norikazu, Matsuda Yasuo, Amano Hisao: Power conversion system, EP 0293 869 A2, European patent, Jan. 1988

[13] Søren Poulsen: Single Conversion Isolated Impedance Transformation Amplifier, WO 2004/001960 Al, Int. patent, Dec. 2003 